\title{
What is the future of social work?
}

\author{
M. Lavalette (Ed.) \\ Bristol: Policy Press 2019 \\ ISBN 978-1-4473-4082-9, paperback, pp.200, NZD35.90
}

S ocial work faces profound challenges after 40 years of neoliberalism. Financial cuts, political interventions, marketisation and welfare changes have reshaped the relationship between individuals and the state, all of which have led to the title and question this publication aims to answer. It is timely and welcome and, although focussing on the UK, it is clear from the international social work literature that neoliberalism and policies of austerity have had severe impact globally.

The book arose from a series of lectures by distinguished academics given at Liverpool Hope University with each writing up their talk into a chapter for this book. The editor, Michael Lavalette, provides an introduction and conclusion as well as a chapter on austerity and social work, while the other contributors look at the practice areas of child protection, adult care and mental health, as well as practice issues surrounding older people, neoliberalism, neo-eugenics and refugees. Only a few of the chapters can be mentioned here.

Considering my practice experience, perhaps it is no surprise that Brid Featherstone's stood out. She rightly bemoans a child protection practice based on procedures, risk assessment and multi-agency working focussing on the actions / inactions of parents / carers. Instead the argument is for a social model, one that focuses on the economic, social and cultural barriers faced by individuals and families and the sociorelational pressures they face (Featherstone et al., 2018). In short, improving the economic and social circumstances of families must be at the heart of child protection rather than individualised notions of risk and responsibility which act to reinforce the already oppressive circumstances of the marginalised.

John Harris's on the social work labour process was another which resonated with my early practice experience. Although social work offices in the 1970s were often referred to by radicals as 'Seebohm factories' because social work was increasingly like a job in a factory, this was always an exaggeration. As Harris notes, there was often a permissive culture with supervision sessions often being ad hoc and being left to the practitioner to decide when/whether they happened and what should be discussed. Practitioners could also decide 'how' to practise, by, for example utilising group and community work methods where necessary. However, Harris argues that today's social work labour process, involving the ever more breaking down of tasks and managerial control via IT systems, does make social work less 'professional' and more 'job-like'. In short, the radical "analysis was not wrong; it was simply premature" (p. 140).

Peter Beresford's contribution on service user engagement argues that, instead of social work being geared to working with the most disadvantaged and marginalised, there should a "social work by and for all". Drawing on research with service users on what they thought of palliative care/end of life social work he outlines five principles for the future of social work: universalism; a social approach; treating diversity with equality; a participatory approach to learning, practice, organisation, research and knowledge development and exchange; and gap mending and ending to challenge the divisions that can exist in social work, for example between service users and social 
workers. The overall call is for social work to be a vehicle for benign personal and social change.

Mark Lymbery's chapter on "The slow death of social work with older people?" was an intriguing read. He rightly argues that practice with this service user group is one of the least-developed areas of the profession and outlines the areas where social work is needed. Examples include where there is an onset of physical illness and an increase in physical disability or frailty, when there are significant levels of cognitive impairment through such as dementia or depression, when the needs of carers become important because of increasing physical/mental frailty, and, not least, responding to elder abuse. He goes on to discuss the history of social work with older people, the impact of austerity and future trends including the often-discussed integration of social care with health, which, incidentally, is likely to add to the power of doctors. This is all well and good but, sadly, I was left feeling it difficult to see the value of the question mark at the end of the chapter title.

Lavalette's conclusion asks questions such as "What kind of social work do we want to see, and what kind of profession do we want to be part of?" (p. 161). He does not want it to be one solely shaped by targets and markets whereby practitioners process people at the behest of a brutalising welfare state. Instead it should be a profession that, despite the challenges of neoliberalism, austerity and managerialism, asserts its independence and values. Readers of this journal, like me, will totally agree. It may be timely for a book that poses a similar question to be developed for social work in Aotearoa New Zealand.

\section{Reference}

Featherston, B., Gupta, A., Morris, K. \& White S. (2018). Protecting children: A social model. Bristol, UK: Policy Press. 